\title{
Vaccination coverage for seasonal influenza among residents and health care workers in Norwegian nursing homes during the 2012/13 season, a cross-sectional study
}

\author{
Horst Bentele ${ }^{1,3^{*}}$, Marianne R Bergsaker ${ }^{2}$, Siri Helene Hauge ${ }^{1}$ and Jørgen V Bjørnholt ${ }^{1}$
}

\begin{abstract}
Background: WHO has set a goal of 75\% vaccination coverage (VC) for seasonal influenza for residents and also recommends immunization for all healthcare workers (HCWs) in nursing homes (NHs). We conducted a cross-sectional study to estimate the VC for seasonal influenza vaccination in Norwegian NHs in 2012/2013 since the VC in NHs and HCWs is unknown.

Methods: We gathered information from NHs concerning VC for residents and HCWs, and vaccination costs for HCWs, using a web-based questionnaire. We calculated $\mathrm{VC}$ among NH residents by dividing the number of residents vaccinated by the total number of residents for each NH. VC among HCWs was similarly calculated by dividing the number of HCWs vaccinated by the total number of HCWs for each $\mathrm{NH}$. The association between VC and possible demographic variables were explored.

Results: Of 910 NHs, 354 (38.9\%) responded. Median VC per NH was 71.7\% (range 0-100) among residents and 0\% (range 0-100) among HCWs, with 214 (60\%) NHs reporting that none of their HCWs was vaccinated. Median VC for HCWs in NHs with an annual vaccination campaign was 0\% (range 0-53), compared to when they did not have an annual vaccination campaign 0\% (range 0-12); the distributions in the two groups differed significantly (Mann-Whitney $\mathrm{U}, \mathrm{P}=0.006$ two tailed).

Conclusion: Median influenza VC in Norwegian NHs was marginally lower than recommended among residents and exceptionally low among HCWs. The VC in HCWs was significantly higher when NHs had an annual vaccination campaign. We recommend that NHs implement measures to increase VC among residents and HCWs, including vaccination campaigns and studies to identify potential barriers to vaccination.
\end{abstract}

\section{Background}

Residents in nursing homes (NHs) and long-term care facilities (LTCF) are at higher risk of severe respiratory tract infections owing to old age, the number of underlying illnesses, and close living conditions [1-3]. The main vaccine- preventable respiratory tract infection is caused by the influenza virus. The infection can be

\footnotetext{
* Correspondence: horst.bentele@fhi.no

'Department of Infection Control Epidemiology, Norwegian Institute of Public Health, Oslo, Norway

${ }^{3}$ European Programme for Intervention Epidemiology Training (EPIET), European Centre for Disease Prevention and Control (ECDC), Stockholm, Sweden

Full list of author information is available at the end of the article
}

severe and even lethal, and viral infections often predispose sufferers to bacterial secondary infections and complications [4]. Further, although the lethality of influenza infection is low, the resulting reduced general condition following infection is of major importance in the elderly. Accordingly, the World Health Organization (WHO) defines NHs residents as a risk group for severe influenza and recommends vaccination coverage (VC) of at least $75 \%$. The main goals are to reduce risk of severe disease and to prevent outbreaks. The WHO recommendation also includes influenza vaccination of health care workers (HCWs) in order to prevent introduction of the disease into healthcare institutions [5,6]. The Norwegian guidelines for infectious disease control follow the WHO 
recommendations relating to seasonal influenza, the aim being to achieve a minimum VC of $75 \%$ in Norwegian $\mathrm{NHs}$ [7]. Seasonal influenza vaccination for residents in NHs is reimbursed by the state in Norway. This is in contrast to influenza vaccination of HCWs, for whom each employer decides whether it is to be given free of charge. The yearly influenza vaccination is normally conducted during October and November [7].

The Vaccine European New Integrated Collaboration Effort (VENICE) report, covering the 2011/2012 season, showed seasonal influenza VC for the general Norwegian population above 65 years and for all HCWs to be $36 \%$ and $12 \%$ respectively [8]. However, the $\mathrm{VC}$ among residents and HCWs in NHs is unknown. To guide development of vaccination programs for residents and HCWs in NHs, data on VC is crucial. We therefore conducted a cross-sectional study approaching all NHs in Norway in order to estimate $\mathrm{VC}$ for seasonal influenza vaccine among both residents and HCWs. In addition, we investigated whether there was an association between $\mathrm{VC}$ and response rate by county, yearly vaccination campaigns among residents and $\mathrm{HCWs}$, free-of-charge vaccination of $\mathrm{HCWs}, \mathrm{NH}$ size (number of residents) and geographic location.

\section{Methods}

\section{Population and data collection}

In December 2012 we invited NH managers and $\mathrm{NH}$ physicians to participate in an electronic survey. The invitation was sent to all 429 municipalities in Norway with the instruction to forward the e-mail to all the NHs located in the respective municipality. After six weeks a reminder was sent to the same e-mail-addresses. The total number of residents in NHs in the different counties was obtained from Statistics Norway [9]. In 2011, $910 \mathrm{NHs}$ with a total of 34,795 long-term-care residents were registered in Norway.

The questionnaire (Additional file 1) was developed in QuestBack to collect aggregated data from each $\mathrm{NH}$. The questionnaire contained 10 closed questions regarding seasonal influenza vaccination of residents and HCWs. We also collected general information from the $\mathrm{NHs}$, including geographic location, number of longterm-care residents, number of personnel working in direct contact with the residents, whether influenza vaccination of HCWs was given free of charge and, if not, how much personnel had to pay, and if the NHs had annual vaccination campaigns.

\section{Definitions and data analyses}

In Norway, a $\mathrm{NH}$ is defined as residential facilities for elderly people with the primary purpose of providing a continuous 24-hour professional health-care service. In this study we only included long-term-care residents with registered home address at the NHs, since their medical service, including vaccination, is provided by the $\mathrm{NH}$. We defined a resident as a person with registered home address at the $\mathrm{NH}$. We defined an $\mathrm{HCW}$ as an employee at an $\mathrm{NH}$ who has regular physical contact with the residents. This includes doctors, nurses, auxiliary nurses, occupational therapists, physiotherapists, and students.

$\mathrm{VC}$ among $\mathrm{NH}$ residents was calculated by dividing the number of residents vaccinated by the total number of residents for each NH. Similarly, VC among HCWs was calculated by dividing the number of HCWs vaccinated by the total number of $\mathrm{HCWs}$ for each $\mathrm{NH}$, thereby defining $\mathrm{NH}$ as unit of analysis. $\mathrm{VC}$ is presented as median per county to avoid revealing the $\mathrm{NH}$ identity on a municipality level. We compared the $\mathrm{VC}$ between $\mathrm{NHs}$ where HCWs had to pay for their vaccination and those who got it for free using a Mann-Whitney U-test. Similarly, we compared the VC in both residents and HCWs in NHs who had an annual vaccination campaign and those who did not. Further associations were examined by correlation analyses (Spearman rank test). The statistical analyses were done in Excel 2010 and Stata12. A p-value $\leq 0.05$ was considered significant [10].

All data collected were aggregated. Complete anonymity for persons and NHs was given and therefore ethical approval in Norway not mandated. Participation in the study was voluntary.

\section{Results}

How many of the $910 \mathrm{NHs}$ actually received the invitation is unknown since distribution was by means of generic municipality e-mail addresses. However, 391 of the intended 910 invitees in Norway (43.0\%) responded to our survey. We excluded $37 \mathrm{NHs}$ on the basis of incomplete data; thus 354 (38.9\%) NHs were included in the analysis. These 354 NHs were located in 244 (57\%) of the 429 municipalities in Norway, with representatives from all 19 counties. The response rate by county ranged from $26.7 \%$ in Buskerud to $65.5 \%$ in Finnmark (Table 1).

The 354 NHs included in the study provided aggregated information on a total of 14,208 residents and 28,237 HCWs. The median number of long-term-care residents per NH was 33 (range 1-168). The median number of HCWs per NH was 60 (range 15-400). The high number of HCWs is explained by the fact that we included aggregated data about all NH HCWs in our survey, independent of $\mathrm{NH}$ department, since they usually rotate and hence work both in long- and short-term-care.

\section{Seasonal influenza vaccination coverage}

In the season $2012 / 13,54 \%$ of the NHs had a VC among residents below $75 \%$ and in $15 \%$ of $\mathrm{NHs} \mathrm{VC}$ among residents was below 50\% (Figure 1), the median VC being 
Table 1 Response rate and vaccination coverage (VC) among long-term-care residents and HCWs of the responding NHs (n=354), by county

\begin{tabular}{|c|c|c|c|c|c|}
\hline \multirow[t]{2}{*}{ County } & \multirow[t]{2}{*}{ Response rate (\%) } & \multicolumn{2}{|c|}{ Long term care residents } & \multicolumn{2}{|c|}{ HCWs } \\
\hline & & Median number (range) & Median VC (range) & Median number (range) & Median VC (range) \\
\hline Akershus & $21 / 66(31.8)$ & $32(22-130)$ & $71.4(19.2-88.9)$ & $65(30-395)$ & $0(0-14.7)$ \\
\hline Aust Agder & $14 / 30(46.7)$ & $33(8-66)$ & $60.6(0-100)$ & $58(33-150)$ & $0(0-6.3)$ \\
\hline Buskerud & $12 / 45(26.7)$ & $40(20-108)$ & $61.3(15.4-91.9)$ & $54(17-400)$ & $0(0-9.6)$ \\
\hline Finnmark & $19 / 29(65.5)$ & $16(6-40)$ & $75.0(18.8-100)$ & $35(17-85)$ & $0(0-29.4)$ \\
\hline Hedmark & $16 / 39(41.0)$ & $42(23-110)$ & $59.7(22.7-100)$ & $74(35-247)$ & $0(0-3.0)$ \\
\hline Hordaland & $34 / 86(39.5)$ & $33(9-143)$ & $69.5(25.0-100)$ & $55(15-300)$ & $0.3(0-22.2)$ \\
\hline Møre og Romsdal & $27 / 67(40.3)$ & $28(5-76)$ & $79.3(28.1-100)$ & $49(12-110)$ & $0(0-18.2)$ \\
\hline Nordland & 22/74 (29.7) & $29(9-83)$ & $66.7(10.7-100)$ & $60(15-140)$ & $2.5(0-42.9)$ \\
\hline Nord-Trøndelag & $15 / 36(41.7)$ & $32(8-86)$ & $70.0(18.5-92.1)$ & $50(22-200)$ & $0(0-5.7)$ \\
\hline Oppland & $11 / 39(28.2)$ & $40(25-81)$ & $54.8(0-100)$ & $90(55-154)$ & $0(0-3.0)$ \\
\hline Oslo & 20/58 (34.5) & $73(11-168)$ & $70.8(37.5-100)$ & $110(16-400)$ & $1.7(0-8.6)$ \\
\hline Rogaland & $38 / 72(52.8)$ & $31(1-120)$ & $83.3(0-100)$ & $70(15-300)$ & $0(0-53.3)$ \\
\hline Sogn og Fjordane & 16/34 (47.1) & $33(16-68)$ & $77.0(29.4-98.1)$ & $60(24-110)$ & $4.4(0-25.0)$ \\
\hline Sør-Trøndelag & 25/56 (44.6) & 34 (13-91) & $69.1(27.7-100)$ & $50(25-158)$ & $0(0-33.3)$ \\
\hline Telemark & $11 / 30(36.7)$ & $38(14-74)$ & $71.4(44.4-93.3)$ & $60(35-140)$ & $0(0-28.6)$ \\
\hline Troms & 12/43 (27.9) & $28(8-76)$ & $74.5(35.2-100)$ & $59(19-220)$ & $0(0-22.2)$ \\
\hline Vest Agder & 10/33 (30.3) & $22(6-106)$ & $82.6(58.3-100)$ & $35(20-170)$ & $0(0-13.8)$ \\
\hline Vestfold & 13/34 (38.2) & $42(12-80)$ & $63.2(40.0-93.3)$ & $68(39-195)$ & $0(0-6.1)$ \\
\hline Østfold & 19/39 (48.7) & $51(14-121)$ & $77.7(5.4-100)$ & $110(25-170)$ & $0(0-16.7)$ \\
\hline
\end{tabular}

* The true denominator is not known; the figures underestimate the true coverage, see Discussion.

71.7\% (range 0-100) for all participating NHs. In six counties, the median $\mathrm{NH} \mathrm{VC}$ was above $75 \%$, including one county with a VC of $83.3 \%$ (range 0-100) (Figure 2). We did not find an association between the response rate by county and vaccination coverage among residents (Spearman rank test; rho 0.35; $\mathrm{P}=0.15$ ).

For HCWs, the median vaccination coverage was $0 \%$ (range 0-100) (Table 1), with 214 (60\%) NHs reporting that none of their HCWs was vaccinated.

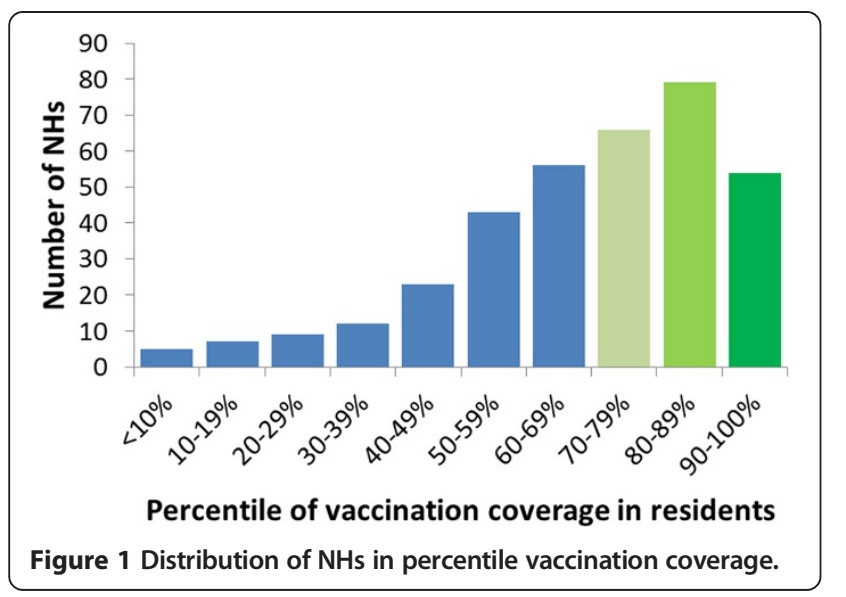

\section{Financing influenza vaccination for HCWs}

Of the 354 responding NHs, 165 (46.6\%) provided information on vaccination cost for HCWs. The vaccination was free of charge in 143 (86.7\%) NHs [median vaccination coverage for employees free of charge $3.6 \%$ ( $\min 0$, $\max$ $53.3 \%$ )] while in $22 \mathrm{NHs}$ employees had to pay for their own influenza vaccination [median vaccination coverage for employees who had to pay $3.6 \%$ ( $\min 0$, max $13.3 \%$; $\mathrm{P}=0.47)$ ]. The price varied between 1.50-25 Euros.

\section{Vaccination promotion}

Of the 354 participating NHs, 316 (89.3\%) answered that they had performed an annual vaccination campaign, 38 did not promote annual vaccination campaigns or the issue was unknown to them. Median VC for HCWs in the NHs having an annual vaccination campaign was 0\% (range 0-53), compared to when they did not have an annual vaccination campaign $0 \%$ (range $0-12$ ); the distributions in the two groups differed significantly (Mann-Whitney U, P $=0.006$ two tailed). Our data showed no difference between the VC of residents in $\mathrm{NHs}$ with an annual vaccination campaign (median 72.4) and those without a vaccination campaign (median 68.5; $\mathrm{P}=0.27$ ). 


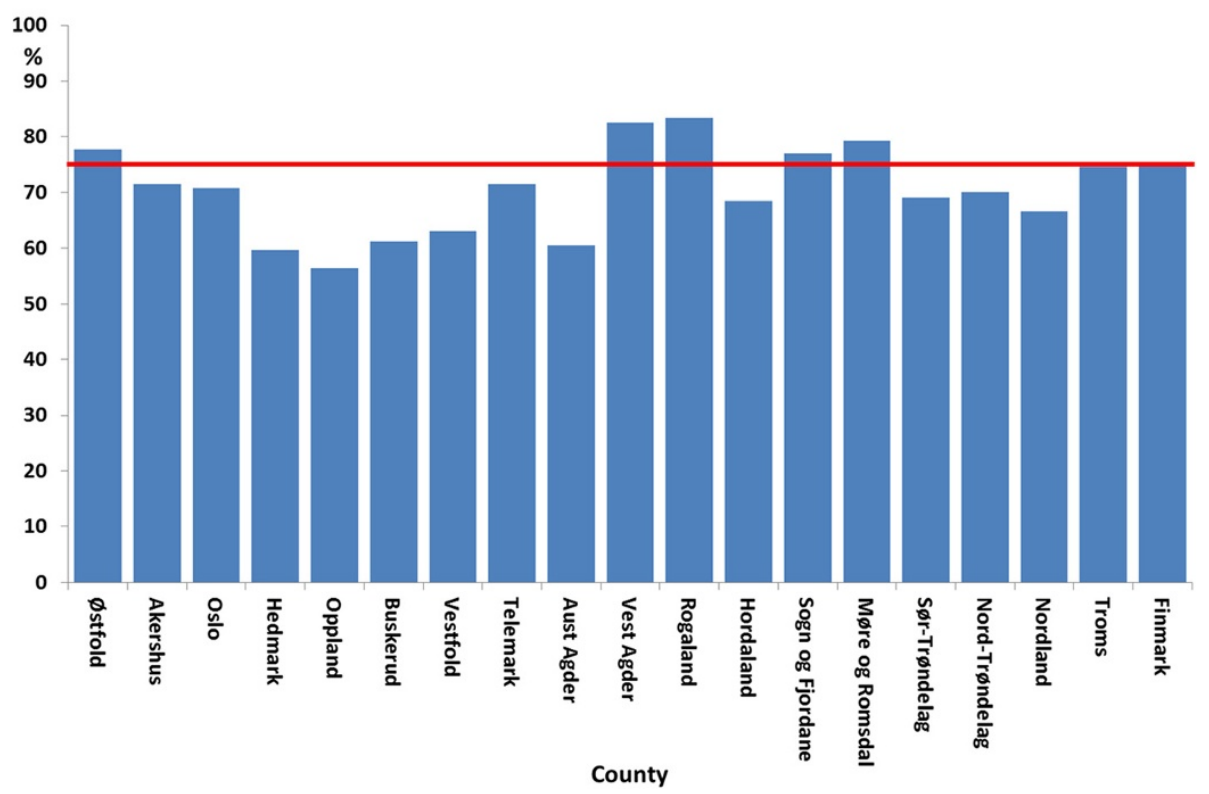

Figure 2 Median vaccination coverage among residents per $\mathrm{NH}$ in $\%$ for each county.

\section{Discussion}

To the best of our knowledge, this is the first study to aim at providing data on $\mathrm{VC}$ for seasonal influenza vaccine among residents and HCWs in Norwegian NHs.

In around half of the NHs, VC for seasonal influenza vaccination among residents was below the $75 \%$ recommended by WHO and laid down in National guidelines. However, the $\mathrm{VC}$ of $\mathrm{NH}$ residents was markedly higher than that in the general population above 65 years of age [8]. This may reflect both the impact of the vaccination recommendations' specifically focusing on $\mathrm{NH}$ residents and awareness of vaccination of residents as an important infection control measure. There are, however, still NHs with no residents vaccinated; thus a substantial effort is still required in order to reach the overall target of $75 \%$.

Vaccination of HCWs has been shown to play an important role in controlling transmission of influenza to residents [5]. A review from the Norwegian Knowledge Center for the Health Services came to the conclusion that influenza vaccination in HCWs reduced the risk of acquiring influenza- like illness in residents by $50 \%$ [11]. On the other hand, a recent Cochrane review shows that, when using laboratory confirmed influenza as an endpoint [12], there is insufficient evidence to prove the effect of vaccinating HCWs in relation to the transmission of influenza to residents. The Cochrane review, however, did not take influenza like illness (ILI) and all-cause mortality of residents into consideration, The impact of vaccinating HCWs has been discussed in several articles. Potter [13] and Carman [14] took ILI into consideration in their studies and found a significant association between HCWs' vaccination against influenza and reduced rates of mortality in residents of NHs, showing how important it is to vaccinate HCWs. HCW absence from work owing to influenza is another important issue and has been studied by several authors [13,15-17]. These studies demonstrate reductions in work-time lost owing to illness among vaccinated HCWs. Moreover, in all of these studies, unvaccinated HCWs with influenza continued to work while symptomatic and may have infected residents. WHO also recommends the vaccination of HCWs against seasonal influenza in two other respects: One, as an effective measure in decreasing the extent of seasonal influenza and two, as a measure towards maintaining an active workforce during influenza epidemics $[5,6]$. As studies in other European countries have shown [18-22], we expected a low VC. Our results are markedly lower than the results of the VENICE project on influenza VC among all HCWs (12\%), which is based on a telephone survey of the general Norwegian population and the numbers of influenza vaccines sold [8]. Most HCWs, however, are employed by hospitals, which conduct more comprehensive infection control. It is thus not unlikely that VC among HCWs in hospitals is higher than in NHs. We therefore suppose that our findings are more likely to reflect the actual $\mathrm{VC}$ among HCWs in NHs. 
In order to raise VC among HCWs, several hospitals in the USA have already made seasonal influenza vaccination mandatory for $\mathrm{HCWs}$ with direct patient contact $[23,24]$. In the Netherlands too, mandatory vaccination programs are being discussed owing to low VC among HCWs working in NHs. The authors of a Dutch study concerning the ethical aspects of mandatory vaccination conclude that NHs have a moral responsibility to implement vaccination programs with a view to getting their HCWs to accept voluntary vaccination, but that this does not exclude the possibility of introducing mandatory vaccination if $\mathrm{VC}$ rates don't rise [25].

The results of our study show that having to pay for the vaccine does not affect the $\mathrm{VC}$ of $\mathrm{HCWs}$ while having annual vaccination campaigns does lead to increases in VC. In the Netherlands, vaccination campaigns have also been found to increase $\mathrm{VC}$ while, interestingly, having to pay for the vaccine as a $\mathrm{HCW}$ in a hospital actually decreased VC [22].

The low VC among HCWs warrants studies to see why they are so reluctant to be vaccinated. Specifically, research into the reason for low $\mathrm{VC}$ in $\mathrm{HCWs}$, as well as into behavioral changes that are positively associated with VC are needed. In the Netherlands, studies have revealed a number of important, significant attitudes held by HCWs in relation to influenza vaccination. These include the responsibility not to harm patients, the knowledge that the vaccine has high efficacy, and the belief that they (HCWs) are in a high risk group in relation to contracting influenza infection $[22,25,26]$.

One limitation in our study is the low response rate. We initially intended to reach all NHs through the generic e-mail addresses of the municipalities, as we do not have access to direct telephone and e-mail lists. More than half of the NHs did not reply and any generalization from the results should therefore be treated with caution. While the e-mail modality is fast and convenient and allows for the respondents to collect the requested data, it may also result in lower response rates compared to telephone modality interviews as undertaken in Venice $[8,27]$. We did not, however, find an association between the response rate per county and the VC. All the same, non-participating NHs could be vaccinating fewer residents, resulting in an overestimation of the $\mathrm{VC}$ and introducing bias towards "the best in the class".

The extent to which NHs document vaccination is unknown and we are unable to state if, and how much, this influences our results.

\section{Conclusion}

From the results of our study, we are able to conclude that the median influenza $\mathrm{VC}$ among residents of the participating $\mathrm{NHs}$ is not much lower than recommended. On the other hand, influenza $\mathrm{VC}$ among HCWs in the participating NHs is exceedingly low. VC in HCWs was significantly higher when NHs had an annual vaccination campaign. We recommend immediate measures be implemented to increase $\mathrm{VC}$ in residents and, especially, in HCWs. These measures should encompass vaccination campaigns and studies to identify potential barriers to vaccination. In order to achieve more comprehensive and accurate data in future, a direct communication channel with NHs should be established.

\section{Additional file}

Additional file 1: Copy of the questionnaire sent to the municipalities for distribution to all their nursing homes (NHs). Translated from the Norwegian original.

\section{Competing interests}

The authors declare that they have no competing interests.

\section{Authors' contributions}

$\mathrm{HB}$ was responsible for the idea, planning, conceptualizing and implementation of the study, interpreting the data and writing the manuscript. JVB made substantial contributions to the planning and conceptualizing of the study, interpretation of results, and drafting and reviewing of the manuscript. SHH was involved in planning the study and contributed to the drafting and revision of the manuscript in relation to important subject specific content. MRB contributed to the drafting and revision of the manuscript in relation to important subject specific content. All authors read and approved the final manuscript.

\section{Acknowledgements}

We would like to thank all participating Norwegian nursing homes for their contributions. Special thanks to Oliver Kacelnik and Anneke Steens for their assistance and contributions. I would also like to thank all the FETP coordinators, Katrine Borgen, Daniela Schmid and Alicia Barrasa, for their excellent suggestions and advice.

\section{Author details}

${ }^{1}$ Department of Infection Control Epidemiology, Norwegian Institute of Public Health, Oslo, Norway. ${ }^{2}$ Department of Vaccines, Norwegian Institute of Public Health, Oslo, Norway. ${ }^{3}$ European Programme for Intervention Epidemiology Training (EPIET), European Centre for Disease Prevention and Control (ECDC), Stockholm, Sweden.

Received: 24 September 2013 Accepted: 30 April 2014

Published: 9 May 2014

\section{References}

1. Gavazzi G, Krause KH: Ageing and infection. Lancet Infect Dis 2002, 2(11):659-666.

2. Liang SY, Mackowiak PA: Infections in the elderly. Clin Geriatr Med 2007, 23(2):441-456.

3. Juthani-Mehta M, Quagliarello VJ: Infectious diseases in the nursing home setting: challenges and opportunities for clinical investigation. Clin Infect Dis 2010, 51(8):931-936.

4. Short KR, Habets MN, Hermans PW, Diavatopoulos DA: Interactions between Streptococcus pneumoniae and influenza virus: a mutually beneficial relationship? Future Microbiol 2012, 7(5):609-624.

5. WHO weekly epidemiological record; Vaccines against influenza WHO positioning paper - nov. 2012, No. 47. 2012, 87, 461-476. Available at [http://www.who.int/wer/2012/wer8747.pdf?ua=1]

6. WHO: Influenza seasonal. In, Fact sheet $N^{\circ} 211$ [Internet]. 2009. Available from: http://www.who.int/mediacentre/factsheets/fs211/en/.

7. NIPH: Smittevernhåndbok. Oslo: Norwegian Institute of Public Health; 2009. http://www.fhi.no/publikasjoner-og-haandboker/smittevernboka. 
8. VENICE: Venice Report; Seasonal influenza vaccination in EU/EEA, influenza season 2011-12. [http://venice.cineca.org/NENICE_Seasonal_Influenza_201112_1.2v.pdf]

9. $\mathrm{SSB}$; Cartographer: Plasser i institusjoner for eldre og funksjonshemmede. In Norway Statistics; 2011. www.ssb.no/statistikkbanken/SelectVarVal/Define.asp? MainTable=InstitPlasser\&KortNavnWeb=pleie\&PLanguage $=0 \&$ checked=true

10. Altman Douglas GA,M: Practical statistics for medical research. London: Chapman \& Hall; 1991:365-395.

11. Vist GESI: Helseeffekt av influensavaksine til eldre og kronisk syke. In Nasjonalt kunnskapssenter for helsetjenesten. 2009. ISSN 1890-1298.

12. Thomas RE, Jefferson T, Lasserson TJ: Influenza vaccination for healthcare workers who work with the elderly: systematic review. Vaccine 2010, 29(2):344-356.

13. Potter J, Stott DJ, Roberts MA, Elder AG, O'Donnell B, Knight PV, Carman WF: Influenza vaccination of health care workers in long-term-care hospitals reduces the mortality of elderly patients. ACP J Club 1997, 127(1):1.

14. Carman WF, Elder AG, Wallace LA, McAulay K, Walker A, Murray GD, Stott DJ Effects of influenza vaccination of health-care workers on mortality of elderly people in long-term care: a randomised controlled trial. Lancet 2000, 355:8.

15. Wilde JA, McMillan JA, Serwint J, Butta J, O'Riordan MA, Steinhoff MC: Effectiveness of influenza vaccine in health care professionals. JAMA 1999, 281:10.

16. Yassi A, Kettner J, Hammond G, Cheang M, McGill M: Effectiveness and cost-benefit of an influenza vaccination program for health care workers. Can J Infect Dis 1991, 2(3):101-108.

17. Smedley J, Poole J, Waclawski E, Stevens A, Harrison J, Watson J, Hayward A Coggon D: Influenza immunisation: attitudes and beliefs of UK healthcare workers. Occup Environ Med 2007, 64:223-227.

18. Mereckiene J, Cotter S, D'Ancona F, Giambi C, Nicoll A, Levy-Bruhl D: Differences in national influenza vaccination policies across the European Union, Norway and Iceland 2008-2009. Euro Surveill 2010, 15:44.

19. Vaux S, Noel D, Fonteneau L, Guthmann JP, Levy-Bruhl D: Influenza vaccination coverage of healthcare workers and residents and their determinants in nursing homes for elderly people in France: a cross-sectional survey. BMC Public Health 2010, 10:159.

20. Kyaw MH, Wayne B, Holmes EM, Jones IG, Campbell H: Influenza and pneumococcal vaccination in Scottish nursing homes: coverage, policies and reasons for receipt and non-receipt of vaccine. Vaccine 2002, 20(19-20):2516-2522.

21. Shroufi ACJ, Vivancos R, Slack RCB: Influenza and Pneumococcal vaccine uptake among nursing home ressidents in Nottingham, England: a postal questionnaire survey. BMC Geriatr 2008, 8:11.

22. Van den Dool C, Van Strien AM, den Akker IL, Bonten MJ, Sanders EA, Hak E: Attitude of Dutch hospital personnel towards influenza vaccination. Vaccine 2008, 26(10):1297-1302.

23. Stewart AM: Using state laws to vaccinate the health-care workforce. Public Health Rep 2012, 127:224-227.

24. Sawyer MH, Peddecord KM, Wang W, Deguire M, Miskewitch-Dzulynsky M, Vuong DD: A public health initiative to increase annual influenza immunization among hospital health care personnel: the San Diego Hospital Influenza Immunization Partnership. Am J Infect Control 2012, 40(7):595-600

25. van Delden JJM, Ashcroft R, Dawson A, Marckmann G, Upshur R, Verweij MF: The ethics of mandatory vaccination against influenza for health care workers. Vaccine 2008, 26(44):5562-5566.

26. Looijmans-van Den Akker I, Hulscher ME, Verheij TJ, Riphagen-Dalhuisen J, van Delden JJ, Hak E: How to develop a program to increase influenza vaccine uptake among workers in health care settings? Implementation Sci 2011, 6:47.

27. Dillman DA, Phelpsb G, Tortorab R, Swiftb K, Kohrellb J, Berckb J, Messera $B L$ : Response rate and measurement differences in mixed-mode surveys using mail, telephone, interactive voice response (IVR) and the Internet. Soc Sci Res 2009, 38(1):1-18.

\section{doi:10.1186/1471-2458-14-434}

Cite this article as: Bentele et al:: Vaccination coverage for seasonal influenza among residents and health care workers in Norwegian nursing homes during the 2012/13 season, a cross-sectional study. BMC Public Health 2014 14:434.

\section{Submit your next manuscript to BioMed Central and take full advantage of:}

- Convenient online submission

- Thorough peer review

- No space constraints or color figure charges

- Immediate publication on acceptance

- Inclusion in PubMed, CAS, Scopus and Google Scholar

- Research which is freely available for redistribution 